\title{
RELATO DE EXPERIÊNCIA DA DISCIPLINA "ADMINISTRAÇÃO DA PRODUÇÃO", OFERTADA EXCLUSIVAMENTE EM INGLÊS PARA GRADUANDOS DA UFMG - CAMPUS MONTES CLAROS
}

Giovanni Campos Fonseca ${ }^{1}$

André Luiz Mendes Athayde ${ }^{1}$

Igor Andrade Dias ${ }^{1}$

João Victor de Oliveira e Souza ${ }^{1}$

\section{RESUMO}

Este artigo relata a experiência inédita de oferta de uma disciplina lecionada exclusivamente em inglês para graduandos da Universidade Federal de Minas Gerais, campus Montes Claros. Focalizam-se o contexto da criação da disciplina, os aspectos mais relevantes da construção dela e as principais reflexões geradas a partir da experiência. A primeira oferta da disciplina contou com dezessete estudantes, e a segunda com vinte e dois matriculados. Concluíram o curso, respectivamente, sete e doze acadêmicos. Estudantes relataram, por um lado, dificuldades de cursar uma disciplina em idioma estrangeiro e, por outro lado, satisfação de concluir o curso e de exercitar habilidades na língua inglesa. Embora seja prematuro avaliar as repercussões da oferta da disciplina para a internacionalização do ensino no campus, podese afirmar que ela possibilitou uma oportunidade válida tanto para aqueles estudantes que não têm a oportunidade de ir ao exterior quanto para os que desejam se preparar para tal experiência.

Palavras-chave: Internacionalização do ensino superior. Disciplina em inglês. Graduação.

\footnotetext{
${ }^{1}$ Instituto de Ciências Agrárias, Universidade Federal de Minas Gerais, campus Montes Claros, MG, Brasil.
} 


\title{
EXPERIENCE REPORT OF THE "PRODUCTION MANAGEMENT" DISCIPLINE OFFERED EXCLUSIVELY IN ENGLISH TO GRADUATE STUDENTS IN UFMG - MONTES CLAROS CAMPUS
}

\author{
Giovanni Campos Fonseca \\ André Luiz Mendes Athayde \\ Igor Andrade Dias
}

João Victor de Oliveira e Souza

\section{ABSTRACT}

This paper reports the unprecedented experience of offering a subject taught exclusively in English to undergraduates of the Federal University of Minas Gerais, Montes Claros Campus. It focuses on the creation context of the discipline, the most relevant aspects of its construction and the main reflections generated from the experience. The first offer of the discipline had 17 enrolled students and the second had 22. The course was completed by 7 and 12 academics respectively. Students reported, on the one hand, difficulties in attending a course taught in a foreign language and, on the other hand, satisfaction in completing the course and exercising their English language skills. Even though it is premature to evaluate the repercussions of the subject offer for the internationalization of teaching in the Campus, it can be said that it has provided a valid opportunity, both for those students who do not have the opportunity to go abroad and for those who are preparing for this upcoming experience.

Keywords: Internationalization of higher education. Subject in English. Undergraduation. 


\section{INTRODUÇÃO}

A internacionalização do ensino superior pode ser conceituada como o processo de integrar dimensões internacionais, interculturais ou globais na missão, na função ou na proposta de uma instituição de ensino superior (KNIGHT, 2006 apud YONEZAWA, 2013). Mesmo que o cenário universitário seja heterogêneo, com Instituições de Ensino Superior (IES) de tamanhos e vocações diferentes, a internacionalização do ensino superior destaca-se como um interesse comum e deve - quando adotada - ser abraçada pelas lideranças institucionais, governanças, unidades acadêmicas, estudantes e todas as instâncias de suporte e de serviços acadêmicos (HUDZIK, 2011).

A expansão do uso da língua inglesa - que a faz ser considerada língua global ou internacional impõe uma reflexão sobre as práticas pedagógicas vigentes, considerando-se os novos desafios e conflitos que surgem entre o global e o local. É necessário também que se compreenda melhor a perspectiva dos estudantes, os anseios, receios e crenças deles com relação ao papel do inglês no mundo atual. Da perspectiva da aprendizagem do idioma, há que se considerar a importância do desenvolvimento das diversas habilidades necessárias para a proficiência na língua - como habilidades de fala, de escuta e de compreensão de textos. Dessa forma, tornase necessário enfatizar o ensino do inglês, a exemplo do que ocorreu em outros países que já o fizeram por motivo semelhante. A necessidade de investir no ensino de línguas adicionais na Comunidade Europeia fez com que muitos países europeus assumissem novas políticas de educação no tocante ao ensino de línguas estrangeiras. Algumas comunidades autônomas espanholas, por exemplo, propuseram novas políticas educacionais que culminaram com a proposta de programas de educação bilíngue. Assim, essas comunidades - e várias outras na Europa - começaram a utilizar a abordagem interdisciplinar e plurilinguística (BERNABÉ; MATEOS, 2013). Mais adiante neste artigo, retomaremos essa discussão, abordando o Processo de Bolonha, que é considerado uma das mais expoentes reformas recentes no campo da educação superior europeia.

Após a Segunda Guerra Mundial, um dos efeitos percebidos da globalização na educação superior foi a transformação desta, de um caráter elitizado para um caráter massificado e diversificado, isto é, marcado pelo maior acesso das pessoas às universidades. Outro efeito diz respeito à maior internacionalização da educação superior, facilitada pelo maior compartilhamento de informação através de novas tecnologias, compartilhamento esse realizado principalmente em inglês, no caso de publicações científicas. A globalização - 
Relato de experiência da disciplina "Administração de Produção", ofertada exclusivamente em inglês para graduandos da UFMG - campus Montes Claros

entendida como a interdependência social e econômica entre pessoas e países - afeta o desenvolvimento da educação, relativiza as barreiras geográficas e linguísticas bem como reforça a necessidade de um país elevar o nível educacional que possui, para aproveitar esse potencial de sinergia (FINARDI; ORTIZ, 2014).

Com relação à internacionalização do ensino superior, é necessário ir além de aspectos relacionados à mobilidade acadêmica (FREIRE JÚNIOR, 2015). Outras ações devem ser empreendidas pelas IES brasileiras, como a chamada "Internacionalização em casa" (Internationalization at home), que envolve o desenvolvimento de atividades internacionais na própria instituição, voltando-se para aqueles que não têm a oportunidade de ir ao exterior. A "Internacionalização do currículo", que prevê, dentre outras atividades, a inclusão de componentes internacionais nos currículos dos cursos, o ensino de línguas estrangeiras principalmente o inglês - e o aumento da presença de estudantes e professores estrangeiros - que passa pela oferta de disciplinas em inglês - são algumas das ações que podem ser desenvolvidas.

O processo de internacionalização de uma universidade pública e de uma instituição privada no Sudeste do Brasil foi analisado por Finardi e Ortiz (2014), chegando-se à conclusão de que o maior impeditivo para a internacionalização do ensino superior nas duas universidades estudadas era a baixa proficiência em inglês, o que dificultava tanto a mobilidade acadêmica para o exterior quanto a recepção de acadêmicos estrangeiros nas instituições de ensino superior brasileiras.

Ainteração com instituições de ensino e pesquisa estrangeiras é fundamental para universidades brasileiras que pretendem exercer papéis relevantes na comunidade acadêmica internacional. Nesse contexto, a Universidade Federal de Minas Gerais (UFMG) vem desenvolvendo iniciativas de internacionalização, principalmente pela promoção de intercâmbios de estudantes em programas como o Minas Mundi e o Programa Ciência sem Fronteiras (CsF). O CsF - com a oferta de bolsas de mobilidade no exterior para estudantes e docentes - certamente contribuiu para a internacionalização de parte das instituições de ensino brasileiras (FREIRE JÚNIOR, 2015). A visibilidade internacional obtida poderá ser aproveitada para a construção de parcerias que contribuam para o processo de internacionalização de cada instituição, levando-se em conta os objetivos e vocações desta. É importante reconhecer que tanto as mais tradicionais IES brasileiras - em que a pesquisa atua como motor de desenvolvimento e nas quais o processo 
de internacionalização já é mais desenvolvido - como as IES com menos tradição em pesquisa podem se beneficiar das oportunidades trazidas pela internacionalização.

Embora a realização de intercâmbios seja um esforço importante, a internacionalização efetiva da universidade requer a formalização de acordos e convênios de cooperação com instituições de outros países. Não se pretende aqui alardear a internacionalização da educação superior como panaceia nem a globalização como um destino fatal. A depender da área de conhecimento, certamente há, no Brasil, massa crítica consolidada que se equipara ou supera - por assim dizer - a encontrada em outros países. Reconhecer a importância da internacionalização não significa necessariamente assumir conduta subserviente ou de inferioridade do Brasil ou dos pesquisadores que aqui atuam. Trata-se, pelo contrário, de melhorar as condições de inserção de brasileiros na comunidade acadêmica internacional, com o intuito mesmo de compartilhar os nossos avanços. Essa inserção não se limita à proficiência em idiomas estrangeiros, mas não se pode prescindir dela quando se quer estabelecer relações interpessoais e interinstitucionais que forneçam bases concretas para trocas de experiências e para uma perene cooperação internacional.

O campus Montes Claros, em parceria com a Diretoria de Relações Internacionais da UFMG, vem desenvolvendo um conjunto de ações de apoio à internacionalização dessa unidade acadêmica. Destacam-se - para além da já mencionada participação de estudantes em intercâmbios - ações como a aplicação de testes de proficiência, a exemplo do Test of English as a Foreign Language - Institutional Testing Program (TOEFL ITP), que integram o Programa Idiomas sem Fronteiras (IsF).

A experiência em destaque neste artigo foi a oferta da disciplina denominada Production and Operations Management para estudantes dos cursos de graduação, no segundo semestre de 2016 e no primeiro de 2017. A iniciativa teve como objetivos compartilhar conhecimentos específicos em inglês - idioma das principais publicações da área de Administração da Produção - e oferecer aos estudantes a oportunidade de avaliar e desenvolver o domínio que possuem do idioma em uma estrutura que busca simular a oferta de disciplinas no exterior. Trata-se de uma iniciativa de internacionalização do currículo formal (LEASK, 2015 apud BEELEN; JONES, 2015) e que será relatada nos aspectos mais relevantes da forma como foi construída e nas principais reflexões geradas a partir da experiência. Antes de iniciar a apresentação e a discussão dos dados empíricos, é importante trazer elementos teóricos fundamentais sobre a língua inglesa como meio de instrução e objeto de ensino. 
Relato de experiência da disciplina "Administração de Produção", ofertada exclusivamente em inglês para graduandos da UFMG - campus Montes Claros

\section{A LÍNGUA INGLESA COMO MEIO DE INSTRUÇÃO E OBJETO DE ENSINO}

O "valor da língua" está presente em debates políticos sobre o ensino de línguas estrangeiras. Isso significa que, quanto mais uma língua tem de "valioso", maiores motivos existem para inscrevê-la em programas públicos. É desse raciocínio que partem as recentes recomendações sobre o caráter obrigatório do ensino do inglês.

Nas decisões com relação ao ensino de idiomas estrangeiros nos sistemas educativos, é fundamental analisar a chamada dinâmica das línguas. Pode-se inferir que, em outro momento, as políticas públicas estejam voltadas para o ensino de um idioma que não o inglês, pela influência e pelo valor global de momento desse outro idioma (CHISWICK; MILLER, 1999). Um exemplo desse fenômeno é a oferta - no primeiro semestre de 2018 - do curso de mandarim na UFMG campus Montes Claros, em parceria com o Instituto Confúcio.

O inglês é atualmente a língua mais falada no mundo, o que lhe confere uma característica peculiar. Uma língua internacional ou franca é aquela usada por pessoas de diferentes países para se comunicarem, não necessariamente com falantes nativos, o que representa bem a realidade da língua inglesa (MCKAY, 2002), que não pertenceria mais a um povo específico, mas é propriedade de todos os que a utilizam em nível global (CANAGARAJAH, 1999).

Para entender o papel atual da língua inglesa no Brasil e nas diferentes partes do mundo, é importante conhecer a categorização proposta por Kachru (1985), em três círculos concêntricos: 1) O Inner Circle, formado pelos países onde a língua inglesa é a língua materna (Estados Unidos da América, Austrália, Canadá e Reino Unido); 2) O Outer Circle, composto pelos países que adotam a língua inglesa como segunda língua em contexto multilíngue (Nigéria, Singapura, Índia, Filipinas); e 3) O Expanding Circle, que inclui os países onde a língua inglesa é ensinada como língua estrangeira (casos como o do Brasil e da China).

O ensino de língua inglesa no Brasil precisa ir além de questões metodológicas, sendo crucial considerarem-se as questões políticas envolvidas (LEFFA, 2005). Refletindo sobre a universidade europeia - mas também aplicando as reflexões às universidades em outros continentes -, Boaventura de Sousa Santos (2011) questiona se uma universidade com características globais realmente é possível. A universidade atuou ao longo da história como um dos elementos constitutivos do estado-nação, formando as respectivas elites e a burocracia e fornecendo o conhecimento e a ideologia subjacentes a projetos nacionais. $\mathrm{O}$ autor reconhece a importância 
da internacionalização da educação superior, mas critica os excessos, como o de se avaliar a qualidade da produção acadêmica de acordo com critérios monoculturais.

\begin{abstract}
A universidade moderna foi, desde o início, uma instituição transnacional ao serviço de sociedades nacionais. No seu melhor, a universidade moderna é um modelo pioneiro dos fluxos internacionais de ideias, professores, estudantes e livros. Vivemos num mundo globalizado, mas não num mundo homogeneamente globalizado. Existem não apenas lógicas diferentes que determinam o movimento dos fluxos globalizados, mas também diferentes relações de poder por detrás da distribuição dos custos e dos benefícios da globalização. De par com a ganância transnacional existe uma solidariedade transnacional. De que lado estará a universidade? Tornar-se-á numa empresa transnacional ou numa cooperativa ou organização sem fins lucrativos transnacional? Existe alguma contradição entre a nossa ênfase no desenvolvimento cultural e social e a ênfase de alguns políticos europeus e de think-tanks poderosos no desenvolvimento econômico e a contribuição da universidade para a competitividade global dos negócios europeus? Que razão levou a que alguns dos melhores esforços reformistas fora da Europa (por exemplo, no Brasil) a adotarem o slogan: "Nem Bolonha nem Harvard"? (SANTOS, 2011, p. 3).
\end{abstract}

Como salientado anteriormente, o Processo de Bolonha é uma das mais expoentes reformas recentes no campo da educação superior europeia no que tange ao possível impacto na reorganização de estruturas de educação superior em outros continentes e - em especial - no que diz respeito aos sistemas transnacionais de educação superior, de que o Brasil é parte. A denominada "Declaração de Bolonha" foi assinada em 1999, definindo o escopo político para a educação superior europeia em três vertentes: estabelecer, em um prazo de dez anos, um Espaço Europeu de Ensino Superior, com o objetivo de aumentar a atração de estudantes de outros países e continentes para as universidades europeias; proceder a uma maior coerência e à equivalência no que tange às estruturas dos cursos superiores e ao reconhecimento de estudos e títulos; e incentivar a mobilidade estudantil entre as fronteiras europeias (SIEBIGER, 2011). Sobre os efeitos do Processo de Bolonha, Boaventura de Sousa Santos (2011) lança a seguinte reflexão:

Será que o processo de Bolonha está a capacitar a universidade para entrar no debate sobre modelos de desenvolvimento e paradigmas civilizacionais, ou, pelo contrário, estará a moldá-la para servir de um modo tão acrítico e eficiente quanto possível o modelo dominante decidido pelos poderes instituídos e avaliado pelos novos supervisores 
Relato de experiência da disciplina "Administração de Produção", ofertada exclusivamente em inglês para graduandos da UFMG - campus Montes Claros

da produção universitária, a mando dos mesmos poderes? (SANTOS, 2011, p. 5).

Um dos principais benefícios do Processo de Bolonha foi ter tornado claro que as universidades são centros de produção de conhecimento no sentido mais amplo, promovendo, assim, a interculturalidade. Ademais, o Processo de Bolonha expandiu exponencialmente a internacionalização da universidade europeia (SANTOS, 2011). Tanto o sucesso dessa iniciativa quanto as reflexões críticas a respeito dela interessam ao momento da internacionalização da educação superior no Brasil. Na seção a seguir, iniciam-se a apresentação e a discussão dos dados empíricos da experiência que motivou a redação deste artigo.

\section{A CONSTRUÇÃO DA DISCIPLINA}

A disciplina Production and Operations Managment foi proposta por um professor que havia retornado do estágio doutoral sanduíche de um ano nos EUA, em meados de 2015. Ao concluir o doutorado, e retomar as atividades acadêmicas no primeiro semestre de 2016, o docente encaminhou a sugestão, que foi aprovada pelo Colegiado do Curso de Graduação em Administração, para a oferta, como disciplina optativa, com duração de 45 horas-aula, lecionada exclusivamente em inglês. O curso é uma introdução à Administração da Produção, que é objeto de disciplina obrigatória de 60 horas-aula, em português, ofertada aos graduandos em Administração e muitas vezes cursada como eletiva por estudantes de outros cursos do campus. Dessa forma, o conteúdo discutido não estaria restrito aos estudantes com proficiência necessária para cursá-lo na língua inglesa, já que a disciplina é ofertada também em português.

A iniciativa do professor foi apoiada por um colega graduado em Administração e em LetrasInglês que também ministra disciplinas relacionadas à área de Administração da Produção e que realizou a pesquisa de mestrado sobre o tema da internacionalização do ensino superior em universidades brasileiras, mais especificamente sobre programas de intercâmbio. A dupla de professores compartilhava, portanto, a atuação na mesma área de conhecimento, o interesse pelo inglês e a conviç̧ão de que experiências internacionais são importantes para a formação técnica e para o amadurecimento pessoal dos estudantes. Dessa forma, como anunciado anteriormente neste artigo, a iniciativa de oferta da disciplina tinha o duplo objetivo de abordar conceitos da Administração da Produção na língua inglesa e de oferecer aos estudantes a oportunidade de avaliar e desenvolver o domínio que possuíam do idioma, 
ao vivenciarem uma estrutura que buscaria, em alguma medida, simular uma experiência internacional.

Como se tratava da primeira iniciativa de oferta de disciplina exclusivamente lecionada em idioma estrangeiro na UFMG campus Montes Claros, a primeira incerteza enfrentada pelos professores relacionava-se ao número de estudantes que se matriculariam e se, portanto, a disciplina seria viável. A primeira decisão no sentido de aumentar a atratividade da oferta foi disponibilizá-la no horário das $18 \mathrm{~h} 10 \mathrm{~min}$ às 19 horas. Esse horário poderia viabilizar a participação dos discentes dos cinco cursos diurnos e dos estudantes de Administração, que é o único curso noturno da unidade acadêmica. Como se tratava de uma disciplina de 45 horas-aula, o plano de ensino foi elaborado para três encontros semanais, o que pode ser considerado adequado quando se trata da maior frequência de contato com o idioma estrangeiro, mas que impõe cuidados com relação ao planejamento de cada aula, que ficaria restrita a 50 minutos.

Outro aspecto considerado nas fases iniciais da construção da disciplina foi a escolha das referências bibliográficas. Optou-se por utilizar um livro-texto dos mesmos autores da principal referência da disciplina oferecida em português (SLACK; CHAMBERS; JOHNSTON, 2010). Além do fato de os autores serem reconhecidos na área de conhecimento, os professores consideraram que essa escolha poderia facilitar a compreensão dos conceitos por parte dos estudantes que já teriam cursado a disciplina obrigatória de Administração da Produção, aumentando ainda mais a atratividade da oferta. Incluíram-se ainda, como leituras complementares, artigos de periódicos que discutiam cada um dos seis temas abordados no curso.

Os professores selecionaram dois monitores voluntários que foram recrutados por meio de edital próprio, o que possibilitou formalizar o vínculo com o programa de monitoria da universidade. Dentre as exigências para a seleção, estava ter sido aprovado na disciplina obrigatória oferecida em português e apresentar comprovante de proficiência na língua inglesa.

A construção metodológica da disciplina privilegiava a discussão de casos práticos e, a partir deles, ia situando os conceitos teóricos relacionados. Embora o projeto da disciplina tenha sido compartilhado pelos dois professores, apenas o docente que havia retornado recentemente do estágio doutoral assumiu a responsabilidade por ela. O outro professor participava de 
Relato de experiência da disciplina "Administração de Produção", ofertada exclusivamente em inglês para graduandos da UFMG - campus Montes Claros

algumas aulas e de todas as reuniões de avaliação do desenvolvimento da disciplina. Essas reuniões eram realizadas a cada duas semanas e contavam com a participação dos professores e dos monitores em uma dinâmica inspirada na abordagem da reflexão-na-ação (SCHÖN, 1992, 2000). Essa abordagem baseia-se em conversações reflexivas entre instrutores e aprendizes no caso, professores e monitores, que são docentes aprendizes - para a construção de uma visão compartilhada da situação problemática e para que sejam abertas novas formulações e apontados novos caminhos para as soluções.

A estrutura proposta para a disciplina previa o mesmo ciclo para cada um dos seis tópicos selecionados para o curso. O professor distribuía dez ou mais questões em inglês sobre os quatro ou cinco estudos de casos - presentes no livro-texto - relacionados a cada tópico estudado. Os estudantes liam os casos e respondiam - em português - as questões. Uma sessão (denominada work in class) era reservada para os estudantes dirimirem as dúvidas e complementarem as respostas em sala de aula. Nessa aula, o professor e os dois monitores da disciplina ofereciam suporte individualizado aos estudantes. As duas aulas subsequentes eram destinadas à discussão das questões. Nessas aulas, a turma era dividida em dois subgrupos compostos no início do semestre com base em um teste de inglês de compreensão de leitura e de escuta aplicado aos estudantes. Os integrantes de cada subgrupo e um monitor formavam um círculo para discussão dos casos relacionados ao tópico abordado. O professor - que utilizava apenas o inglês nas interações ao longo da disciplina - encorajava os estudantes a também se expressarem no idioma estrangeiro. Outras duas sessões davam-se no formato de aulas expositivas, quando o professor responsável pela disciplina sistematizava os principais aspectos práticos e teóricos abordados em cada tópico. A avaliação do desempenho dos estudantes incluía respostas aos questionários e participação nas discussões, além da realização de três provas com questões de múltipla escolha em inglês, cada prova abordando dois tópicos tratados na disciplina.

Com relação ao teste de inglês realizado no início do semestre, o procedimento se fazia necessário pelo fato de não haver pré-requisito para se cursar a disciplina. O objetivo era, portanto, identificar minimamente os níveis de compreensão de texto e de habilidade de escuta, para que o acompanhamento a cada estudante pudesse se basear em pontos fortes e fracos que fossem identificados. O teste consistia em três questões abertas sobre um texto de aproximadamente trezentas palavras e em vinte questões sobre diálogos, similares aos testes de proficiência como o TOEFL. Os subgrupos mencionados acima eram formados de modo a distribuir discentes com diferentes níveis de proficiência, para que não se formassem dois 
grupos heterogêneos entre si: um com estudantes com habilidades mais avançadas e outro com estudantes com habilidades menos avançadas. Em outras palavras: buscava-se formar subgrupos que fossem homogêneos, mesmo em sua heterogeneidade.

Em todas as sessões de discussão de casos práticos, mantinha-se a mesma formação de cada subgrupo que era acompanhado pelo mesmo monitor. O professor responsável pela disciplina também acompanhava as discussões, mas não se inseria diretamente nos círculos e evitava intervir nas discussões dos subgrupos. Percebeu-se que, com o passar das aulas, os estudantes ficavam mais à vontade na interação entre eles, e os monitores iam - por recomendação do professor - tornando-se cada vez menos diretivos nos debates. As intervenções dos monitores eram reservadas para momentos em que a discussão deixava de transcorrer, principalmente quando faltava a algum estudante um conceito da disciplina ou alguma palavra ou expressão para construir uma frase em inglês. Essa conduta inspirava-se na noção de Zona de Desenvolvimento Proximal (VIGOTSKI, 2003), ao considerar que - com algum apoio - os estudantes vão avançando no aprendizado e que os próprios colegas são sujeitos privilegiados para oferecer os insumos para o passo adiante que os aprendizes estão na iminência de dar. Em outras palavras, muitas vezes os estudantes aprendem mais com os próprios colegas que com o professor, e a proposta da disciplina reconheceu essa importante faceta do processo ensino-aprendizagem e criou condições para ela se efetivar.

\section{A EXPERIÊNCIA DA PRIMEIRA OFERTA}

A primeira oferta da disciplina ocorreu no segundo semestre de 2016, com a denominação Tópicos Especiais em Administração: Production and Operations Management. Nessa modalidade, a disciplina foi optativa para estudantes do curso de Administração e eletiva para discentes dos demais cursos do campus. O professor responsável solicitou às secretarias dos colegiados dos cursos de graduação que enviassem uma mensagem eletrônica (e-mail) para todos os estudantes, com um documento anexo que detalhava a proposta da disciplina nos principais aspectos: objetivos, metodologia, avaliação e habilidades requeridas no idioma. Dezessete estudantes matricularam-se, e sete deles (41\%) concluíram a disciplina.

Não é objetivo deste artigo analisar o desempenho dos estudantes na disciplina, mas é importante relatar alguns descompassos entre o planejado e o real. As sessões denominadas work in class - reservadas para os estudantes dirimirem em sala de aula as dúvidas e complementarem as respostas às questões sobre os casos práticos - não funcionaram como 
Relato de experiência da disciplina "Administração de Produção", ofertada exclusivamente em inglês para graduandos da UFMG - campus Montes Claros

se pretendia. Os estudantes iniciavam as respostas às questões nessa sessão, em vez de responderem com antecedência e apenas complementarem as respostas com o apoio dos monitores e do professor. Como os estudantes começavam a ler os casos em sala de aula, não havia tempo suficiente sequer para surgirem dúvidas, o que fazia com que os objetivos dessas sessões não fossem alcançados.

As discussões das respostas às questões dos casos práticos, realizadas em subgrupos acompanhadas por cada monitor, apresentaram boa evolução. No início do semestre, apenas alguns estudantes procuravam utilizar o inglês na maior parte do tempo, recorrendo ao português quando Ihes faltava vocabulário no idioma estrangeiro. A maior parte dos discentes se expressava em português no início do semestre e foram incorporando o inglês às verbalizações ao longo do curso. Ao final da disciplina, todos os estudantes tentavam se expressar em inglês e alguns praticamente não recorriam ao português.

Ainda com relação às discussões, nas reuniões quinzenais de acompanhamento da disciplina, os professores - como já salientado aqui - orientavam os monitores a serem menos diretivos, para estimular a participação dos demais estudantes sem ocupar o espaço de expressão dos colegas. Uma constatação relevante foi a de que, mesmo quando os monitores tendiam a ser mais diretivos, os estudantes participavam da discussão, ainda que, para isso, tivessem que interromper a fala dos monitores. Esse aspecto corroborou a hipótese de que seria mais adequado que o professor responsável pela disciplina fizesse o mínimo possível de intervenções durante o desenvolvimento das discussões.

\section{A SEGUNDA OFERTA DA DISCIPLINA}

A segunda oferta da disciplina ocorreu no primeiro semestre de 2017. Dessa vez, a denominação foi Tópicos em Ciências Agrárias: Production and Operations Management. Nessa modalidade, a disciplina foi optativa para estudantes dos seis cursos de graduação do campus, diferentemente da primeira oferta, quando a disciplina foi optativa para estudantes do curso de Administração e eletiva para discentes dos demais cursos do campus. Essa modificação permitiu que todos os estudantes da unidade que se interessaram pela disciplina a incluíssem nas propostas de matrícula no mesmo momento, diferentemente do que havia acontecido no semestre anterior. A matrícula em disciplinas eletivas acontece na UFMG em momento posterior ao da matrícula em disciplinas optativas. Como se decidiu limitar o número de vagas a vinte - devido às especificidades da disciplina -, na primeira oferta a quase totalidade das 
vagas foi ocupada por estudantes de Administração. Novamente o professor responsável solicitou que as secretarias dos colegiados enviassem e-mail para todos os estudantes com informações detalhadas sobre a proposta do curso.

Nessa segunda oferta da disciplina, as vinte vagas foram ocupadas, sendo apenas três delas por estudantes de Administração. Duas estudantes foram matriculadas, por exceção, para além do limite de vinte vagas: uma estudante internacional (da Argentina), em intercâmbio no campus, e uma pós-doutoranda. Constatou-se, portanto, que essa modalidade de oferta possibilitou maior participação de estudantes dos demais cursos da unidade - todos da área de Ciências Agrárias -, o que era mesmo o objetivo da mudança promovida.

Dos 22 estudantes matriculados, doze concluíram a disciplina, resultando em $54 \%$ dos acadêmicos inscritos, face aos $41 \%$ que concluíram a disciplina em 2016 . A principal diferença da segunda oferta com relação à anterior é que discentes dos cursos de Ciências Agrárias demandaram mais esclarecimentos sobre conceitos elementares da disciplina, se comparados aos estudantes de Administração. Esse aspecto exigiu maior dedicação por parte do professor e dos monitores na busca de exemplos de situações de produção ou de eventos cotidianos que possibilitassem melhor compreensão dos conceitos por parte daqueles estudantes. Ressalta-se que, mesmo contando com um número maior de estudantes originados de outros cursos - que não da Administração -, o percentual de acadêmicos que concluíram a disciplina nessa segunda oferta aumentou. Esse dado permite cogitar que foram eficazes os esforços empreendidos para acolher estudantes dos cursos de Ciências Agrárias. De forma geral, os demais aspectos relatados sobre a primeira oferta da disciplina mantiveram-se na segunda experiência.

\section{CONSIDERAÇÕES FINAIS}

A avaliação dos dois primeiros semestres de oferta da disciplina Administração da Produção (Production and Operations Management) exclusivamente em inglês para graduandos da UFMG campus Montes Claros foi considerada enriquecedora pelo professor responsável pela disciplina, pelo professor que participou das discussões sobre a experiência e pelos monitores. O professor responsável pela disciplina declarou que utilizar um idioma estrangeiro durante as aulas o torna mais vigilante sobre o fato de estar ou não sendo compreendido. Para ele, isso faz com que essa atenção se estenda a disciplinas ofertadas em português, já que, a depender do assunto que esteja sendo tratado e dos elementos de contexto fornecidos aos estudantes 
Relato de experiência da disciplina "Administração de Produção", ofertada exclusivamente em inglês para graduandos da UFMG - campus Montes Claros

- muitas vezes insuficientes -, palavras em português podem ser menos compreensíveis do que em inglês.

Comentários dos estudantes matriculados têm expressado, por um lado, dificuldades de cursar uma disciplina em inglês e, por outro lado, satisfação de concluir o curso. Mesmo alguns dos estudantes que desistiram ao longo dos semestres relataram que tomaram consciência da necessidade de desenvolver mais as habilidades na língua inglesa. Ou seja, o fracasso relativo no curso pareceu estimular os estudantes, em vez de desmotivá-los. É o caso de uma estudante que desistiu de cursar a disciplina por entender que as habilidades que possuía no idioma não eram suficientes para um bom aproveitamento da experiência. Essa estudante decidiu viajar para a Nova Zelândia, com recursos próprios, onde permaneceu durante o segundo semestre de 2017, com o objetivo de melhorar o inglês.

Registra-se também que os dois monitores realizaram intercâmbios acadêmicos pela UFMG - um nos Estados Unidos e outro na Holanda - depois das duas ofertas da disciplina aqui relatadas. Ambos disseram que a prática da monitoria os deixou mais confiantes para a experiência internacional que tiveram. Outros casos relevantes são de um estudante que articulou um estágio de trabalho nos Estados Unidos e de outro estudante que está pleiteando vaga para intercâmbio acadêmico em países de língua inglesa.

Seria prematuro avançar aqui em conclusões sobre as repercussões da oferta da disciplina para a internacionalização da UFMG campus Montes Claros. A próxima etapa da avaliação dessa experiência prevê a realização de entrevistas com todos os estudantes que participaram dos dois semestres de oferta da disciplina, o que permitirá uma análise mais aprofundada, a ser compartilhada em breve. Pode-se afirmar, no entanto, que o desenvolvimento de atividades internacionais na própria instituição - a chamada "Internacionalização em casa" parece mesmo possibilitar uma oportunidade válida tanto para aqueles estudantes que não têm condições de ir ao exterior quanto para os que desejam se preparar para tal experiência.

\section{REFERÊNCIAS}

BEELEN, Jos.; JONES, Elspeth. Redefining internationalization at home. In: CURAJ, Adrian et al. (Ed.). The european higher education area. New York: Springer, 2015. p. 59-72.

BERNABÉ, María; MATEOS, Luz. The effects of CLIL from the perspective of in-service teachers in Salamanca. EXEDRA - Educação e Formação, n. 8, p. 200-217, 2013. 
CANAGARAJAH, Suresh. Resisting linguistic imperialism in English teaching. Oxford: Oxford University Press, 1999.

CHISWICK, Barry; MILLER, Paul. Language skills and earnings among legalized aliens. Journal of Population Economics, v. 12, n. 1, p. 63-91, 1999.

FINARDI, Kyria; ORTIZ, Ramón. Globalization, internationalization and education: what is the connection? In: INTCESS14 - INTERNATIONAL CONFERENCE ON EDUCATION AND SOCIAL SCIENCES, 2014, Istambul. Proceedings of INTCESS14 - International Conference on Education and Social Sciences. Istambul: Ocerint, v. 1, p. 45-53, 2014.

FREIRE JÚNIOR, José Celso. Internacionalização de instituições de ensino superior no Brasil. UNESPCIÊNCIA. São Paulo, $1^{\circ}$ abr. 2015. Disponível em: <http://www.unespciencia. com.br/?p=1343>. Acesso em: 25 jan. 2017.

HUDZIK, John. Comprehensive internationalization: from concept to action. Washington D.C.: NAFSA, 2011.

KACHRU, Braj. Standards, codification and sociolinguistic realism: the English language in the outer circle. In: QUIRK, Randolph; WIDDOWSON, Henry (Ed.). English in the world. Cambridge: Cambridge University Press, 1985.

LEFFA, Vilson. O professor de línguas estrangeiras: do corpo mole ao corpo dócil. In: FREIRE, Maximina; ABRAHÃO, Maria; BARCELOS, Ana Maria (Org.). Linguística aplicada e contemporaneidade. São Paulo: ALAB; Pontes, 2005. p. 203-218.

MCKAY, Sandra. Teaching English as an international language: rethinking goals and approaches. Oxford: Oxford University Press, 2002.

SANTOS, Boaventura de Sousa. A encruzilhada da universidade europeia. Revista do SNESUp, v. 41, jul.-ago.-set., 2011.

SCHÖN, Donald. Learning to design and designing to learn. In: INTERNATIONAL CONFERENCE ON THEORIES AND METHODS OF DESIGN, 1992, Gotemburg. Proceedings... Gotemburg: 1992. p. 25-46.

SCHÖN, Donald. Educando o profissional reflexivo: um novo design para o ensino e a aprendizagem. Tradução de Roberto Cataldo Costa. Porto Alegre: Artes Médicas Sul, 2000. 
SIEBIGER, Ralf. O Processo de Bolonha e sua influência na definição de espaços transnacionais de educação superior: a universidade brasileira em movimento. Revista da Faculdade de Educação, ano IX, n. 15, jan./jul., 2011.

SLACK, Nigel; CHAMBERS, Stuart; JOHNSTON, Robert. Operations management. 6. ed. New York: Pearson Education, 2010.

VIGOTSKI, Liev. Psicologia pedagógica. Tradução de Cláudia Schilling. Porto Alegre: Artmed, 2003.

YONEZAWA, Akiyoshi. The internationalization of the university as a response to globalization: an East Asian perspective. In: SHIN, Jung; TEICHLER, Ulrich (Ed.). The future of the post-massified university at the crossroads: restructuring systems and functions. New York: Springer, 2013.

\section{Giovanni Campos Fonseca}

Professor adjunto da Universidade Federal de Minas Gerais, campus Montes Claros. Graduado em Comunicação Social pelo Centro Universitário de Belo Horizonte, mestre em Engenharia de Produção pela UFMG e doutor em Educação pela UFMG. Tem experiência na área de educação e trabalho, atuando nos seguintes temas: formação profissional, administração da produção, inovação e transferência de tecnologia, ergonomia e desenvolvimento local.

giovannifonseca@gmail.com

\section{André Luiz Mendes Athayde}

Professor assistente da Universidade Federal de Minas Gerais, campus Montes Claros. Graduado em Administração pelas Faculdades Santo Agostinho, mestre em Administração Pública pela Universidade Federal de Viçosa (UFV) e doutorando em Administração na Universidade de Brasília (UnB). Tem experiência na área de logística e administração pública, atuando nos seguintes temas: avaliação de leadtimes; métodos e técnicas de avaliação de programas governamentais; administração da produção.

andreluizathayde@outlook.com 


\section{Igor Andrade Dias}

Graduando em Administração na Universidade Federal de Minas Gerais, campus Montes Claros. Monitor voluntário da disciplina Production and Operations Management. Áreas de grande interesse incluem empreendedorismo, inovação, produção e finanças.

igor.andradedias@yahoo.com.br

\section{João Victor de Oliveira e Souza}

Graduando em Administração na Universidade Federal de Minas Gerais. Graduando em Direito nas Faculdades Integradas Pitágoras. Monitor voluntário da disciplina Production and Operations Management. Tem grande afinidade com finanças corporativas e administração da produção.

joaovictoros@icloud.com 